\title{
Survival of Polycythaemia Vera Patients Treated with Radioactive Phosphorus
}

\author{
J. B. HARMAN,* M.D.; E. M. LEDLIE, $\dagger$ M.B., B.S., D.M.R.
}

Brit. med. F., 1967, 2, 146-148

It is now generally agreed that the symptoms of polycythaemia vera can be relieved by haematological control, and that radiophosphorus is an effective way of doing this over the years. There was also the hope that treatment would prolong life by postponing thrombosis and embolism. The purpose of this investigation was to see how far this hope has been realized. Our experience is based on 132 patients seen during 1948-63 inclusive, and in that time 65 have died. All these dead patients had been treated with radiophosphorus, but six of them were given busulphan towards the end of their lives, when they had become resistant to the dosage of radiophosphorus we were prepared to use. The causes of death are given in Table $\mathrm{I}$.

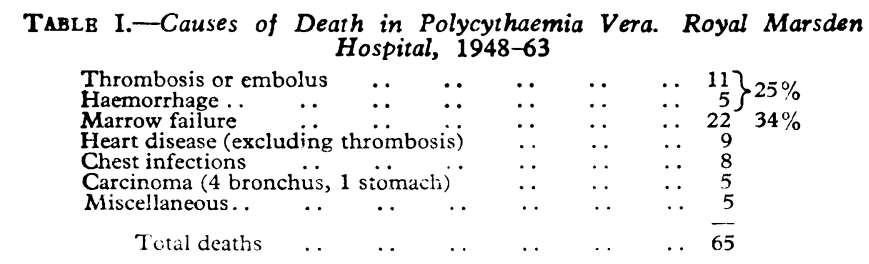

\section{Case-survival Rate Compared with Normal}

The age-corrected survival rates of male and female patients are compared with the normal in Fig. 1. It is clear that the survival time of the polycythaemics is still reduced and that treatment is far from being satisfactory in this respect. ( $P$ at five years: males 0.045 , females 0.048 . At 10 years $P$ is not significant owing to insufficient numbers.)

\section{Survival Compared with Controls}

Nevertheless the survival rates of patients treated with radiophosphorus might still be better than in those who were not so treated. This is a difficult point to settle because there are no very suitable controls. The best that can be found is the series reported by Videbæk (1950). This consists of 125 patients collected from several Danish hospitals between 1920 and 1950. The survival curves are restricted to 66 patients treated for the first time before 1940 and therefore observed for at least 10 years. Comparison suffers from the disadvantage that the two groups were seen in different countries and at rather widely separated dates. They were differently selected; the Danish patients were all those who were diagnosed while attending district hospitals for one reason or another, while most of ours came from a large area and were referred specially because of hopes for a new treatment. The age distribution is also different. Further, the starting-point from which survival is calculated will vary with circumstances, for it is to be expected that the offer of a new cure will stimulate interest in case-finding. The earlier diagnosis that results will appear to improve the prognosis even if none of the patients is benefited. We have calculated survival from the date of first treatment with radiophosphorus.

In view of these difficulties, the best comparison of longevity that we can make is by means of "corrected survival curves" (Berkson and Gage, 1950). The corrected survival is the number of patients who survive to a stated time expressed as a percentage of the number who would have survived that length of time if they had been subjected to the mortality rates which affected the general population of the country concerned. This index thus takes care of the differences due to age, country, and time. The survival curves for the two English series were calculated from cohort mortality rates (Case and Lea, 1962).

The corrected survival curves for normal and polycythaemic Danes is shown in Fig. 2, and it is clear that survival is diminished $(\mathrm{P}$ at five years $<0.001)$. Fig. 3 shows a similar comparison between the Royal Marsden and Videbæk patients. The Royal Marsden Hospital cases have been sex-standardized for direct comparison with the Danish series. It is apparent
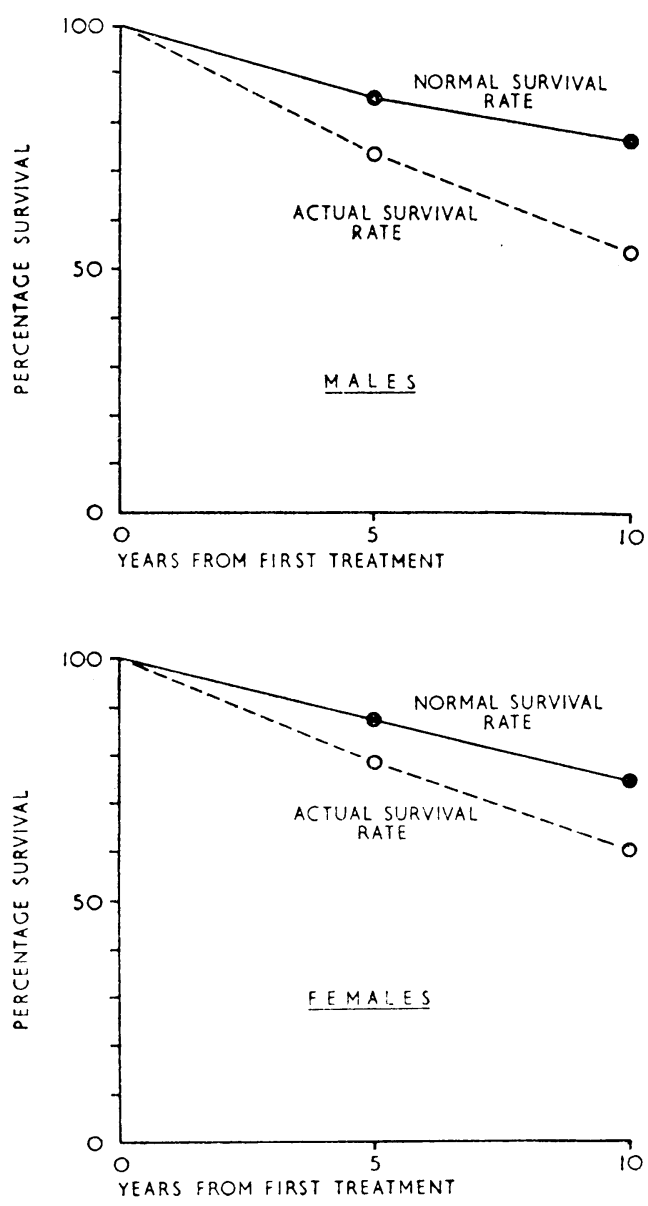

FIG. 1.-Actual and normal survival rates (agecorrected) at 5 and 10 years. Royal Marsden Hospital, 1948-63. Polycythaemia vera. 
that up to 10 years from first treatment the Royal Marsden patients have a better survival curve than those in the Videbæk series ( $P$ at five years $<0.002$ ). It is reasonable to conclude that this improvement is due to radiophosphorus.

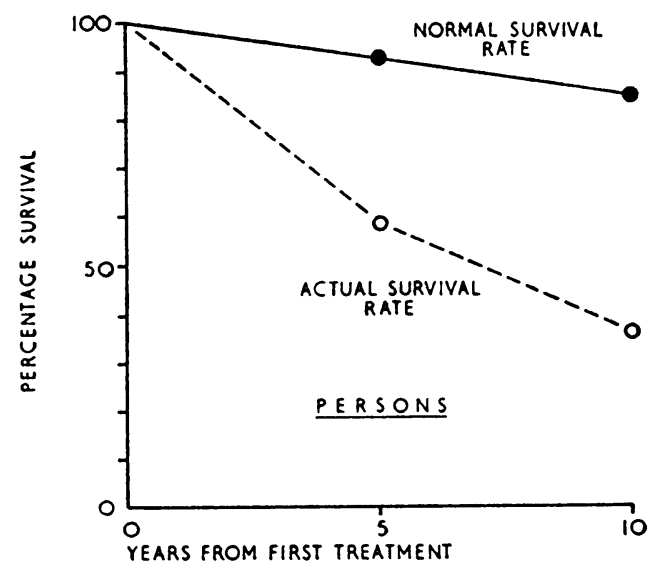

FIG. 2.-Actual and normal survival rates at 5 and 10 years (Videbrek, 1950).

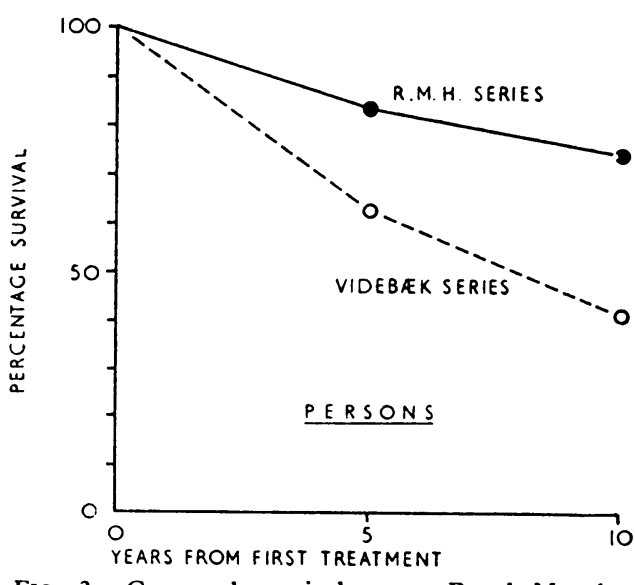

FIG. 3.-Corrected survival rates. Royal Marsden Hospital, 1948-63, and Videbæk (1950).

\section{Survival of Patients Dying with Anaemia}

Table I shows that 22 of our 65 dead patients died of some kind of marrow failure. The onset of marrow failure could usually be recognized without difficulty. Anaemia was a constant feature of these cases, and gross disturbance of granulocyte and platelet production was common. During the course of their illness some of these patients developed changes characteristic of aplasia or myelosclerosis, but a more usual finding was the appearance of immature white cells and often frank leucoblastosis in the blood or marrow. In about a fifth of these cases the marrow failure was acute, lasting a matter of months. In the rest there was a slow increase in the anaemia over several years, five years being the longest. It is clear that this incidence is vastly in excess of that seen in the general population.

There is, however, a tendency for untreated polycythaemics to develop marrow failure, as is shown by references in the literature to patients dying of "aplastic anaemia" or "leukaemia" (Minot and Buckman, 1923 ; Tinney et al., 1945; Erf, 1946 ; Dameshek, 1950 ; Schwartz and Ehrlich, 1950). These accounts are rare, which suggests that the natural incidence is not as high as in treated patients. It is possible that the frequency of this change may have been underestimated in the days when the disease was only recently described, when blood counts were done less often, and when it was not the usual practice to follow groups of patients in special clinics. Nevertheless we think that such a dramatic reversal-patients dying with too little blood after suffering from too muchwould have attracted more attention if it had been seen as often as it has by us and by other observers (Masouredis and Lawrence, 1957 ; Reinhard and Hahneman, 1957 ; Tubiana et al., 1961 ; Modan and Lilienfeld, 1964 ; Osgood, 1964a, 1964b; Perkins et al., 1964; Halnan and Russell, 1965; Modan, 1965 ; Szur and Lewis, 1966).

The only possibility of estimating the increased risk that radiophosphorus-treated patients have of dying of marrow failure is to refer again to Videbæk's series. If we assume that this represents the natural rate of death from marrow failure in polycythaemia we can calculate how many cases we should have seen owing to our increased survival rate. He found two cases of "leukaemia," so for the purposes of this comparison we have used 10 of our cases in which death was attributed to leukaemia-that is, certified as being due to some form of leukaemia. Table II shows that we had three times as many cases as expected. If the other 12 cases of marrow failure are added it becomes obvious that treatment with radiophosphorus is doing something more than merely unmasking a natural tendency. We conclude that this treatment greatly increases it.

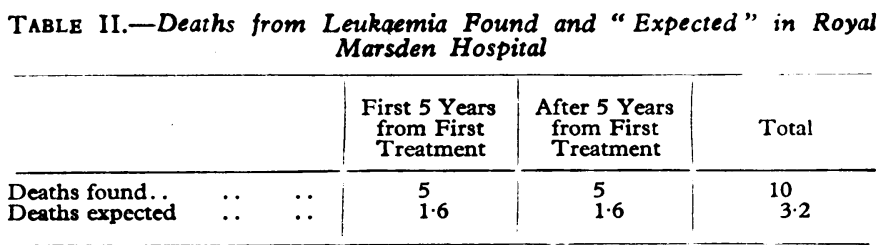

Granted that the mode of death in something like a third of our cases was partly determined by the treatment itself, there is still a question to be answered. Does death from marrow failure occur sooner than death from other causes? The comparison is made in Table III, which shows that the proportion of patients dying from marrow failure and from other causes during the 0 - to 5-year period is slightly lower than the proportion dying during the 5 - to 10 -year period. The numbers, however, are too small for a statistical comparison to be made. Nevertheless there is no evidence that patients dying from marrow failure do die sooner.

Table III.-Royal Marsden Hospital, 1948-63. Comparison of Causes of Death

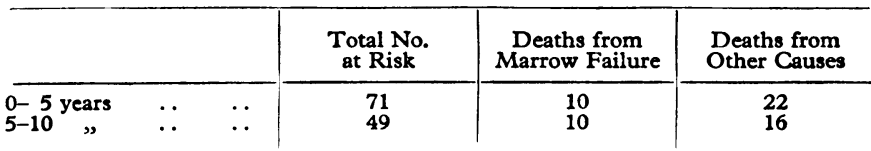

7 patients died later than 10 years -2 from marrow failure and 5 from other causes.

\section{Comparison with Patients Treated by Cytotoxic Drugs}

A series comparable to ours has been reported from Manchester (Perkins et al., 1964), where various cytotoxic drugs were used but no ionizing radiations. We have been able to make a direct comparison of survival through the courtesy of the authors in supplying additional information. Fig. 4 shows the survival curves calculated in the same way as ours. At five years the survival is the same, but at 10 years it is slightly better for the radiophosphorus-treated patients $(P=0.05)$.

It might therefore be argued that from the practical point of view there is little point in trying to determine whether deaths from marrow failure are more or less common with radiophosphorus or cytotoxic drugs-life is as long and the form of death is no worse. The matter is, however, of considerable theoretical interest. Unfortunately we cannot offer any useful comparison between the rates of marrow failure in 
the two groups owing to the difficulties in making a satisfactory definition.

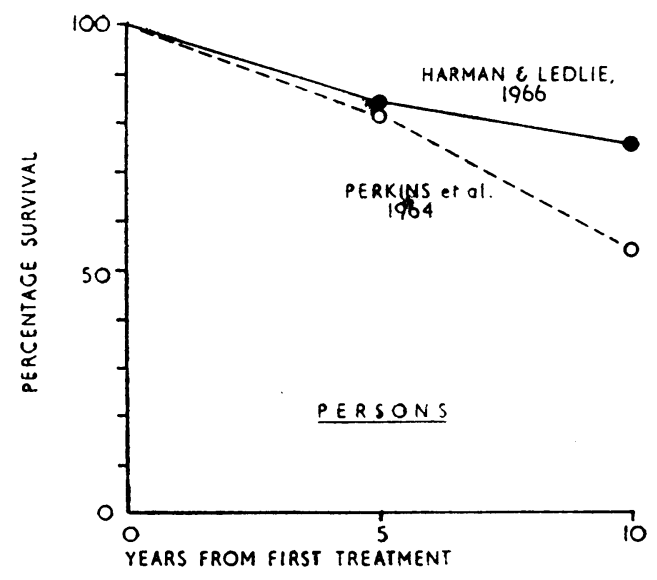

Fig. 4.-Comparison of survival with different treatments. Corrected survival curve.

\section{Summary}

1 here have been 65 deaths among 132 polycythaemic patients treated with radiophosphorus. These are compared with (1) the normal population, (2) a control series collected from before the isotope era, and (3) a recent series in which cytotoxic drugs were used. The following conclusions are drawn: (1) radiophosphorus-treated patients did not live as long as normal persons; (2) they lived longer than the control patients; (3) radiophosphorus increased the incidence of death from marrow failure; (4) there is no evidence that patients dying from marrow failure died sooner than those who died from other causes; and (5) the survival rate of patients treated with cytotoxic drugs was slightly less than that of those treated with. radiophosphorus.

Our thanks are due to Dr. P. E. Thompson Hancock for permission to include his patients in the series. The considerable statistical work involved was done in the Department of Social Medicine, Institute of Cancer Research, and we would like to thank the members of the department, and particularly Miss R. Bell, for much help. We gratefully acknowledge the initiative of Professor D. W. Smithers, Professor of Radiotherapy, in making available the radioactive phosphorus in 1949.

\section{REFERENCES}

Berkson, J., and Gage, R. P. (1950). Proc. Mayo Clin., 25, 27J Case, R. A. M., and Lea, A. J. (1962). Chester Beatty Research Institute. Serial abridged Life Tables, England and Wales, 1841-1960, pt. 1 . London.

Dameshek, W. (1950). F. Amer. med. Ass., 142, 790.

Erf, L. A. (1946). Amer. ₹. Med., 1, 362.

Halnan, K. E., and Russell, M. H. (1965). Lancet, 2, 760.

Masouredis, S. P., and Lawrence, J. H. (1957). Amer. F. med. Sci., 233,

268.

Modan, B. (1965). Blood, 26, 383.

Modand Lilienfeld, A. M. (1964). Lancet, 2, 439.

Osgood, E. E. (1964a). Ibid., 2, 967 .

(1964b). Ұ. Lab. clin. Med., 64, 560.

Perkins, J., Israëls, M. C. G., and Wilkinson, J. F. (1964). Quart. J. Med., 33, 499.

Reinhard, E. H., and Hahneman, B. (1957). f. chron. Dis., 6, 332.

Schwartz, S. O., and Ehrlich, L. (1950). Acta haemat. (Basel), 4, 129.

Szur, L., and Lewis, S. M. (1966). Brit. F. Radiol., 39, 122.

Tinney, W. S., Hall, B. E., and Giffin, H. Z. (1945). Proc. Mayo Clin.,

20, 306.
Tubiana, M., Vallee, G., Boiron, M., and Perez, R. (1961). Nouv. Rev. frans. Hémat., 1, 445 .

Videbæk, A. (1950). Acta med. scand., 138, 179.

\title{
Neurological Presentation of Bacterial Endocarditis
}

\author{
M. J. G. HARRISON,* M.A., B.M., M.R.C.P. ; J. R. HAMPTON,* M.A., D.PHIL., B.M., M.R.C.P.
}

Brit. med. F., 1967, 2, 148-151

In 1885 Osler described the clinical features of malignant endocarditis, and stated that " a considerable number of cases ... come under observation .... for the first time with symptoms of cerebral or even cerebrospinal trouble."

More recent reviews of bacterial endocarditis, though mentioning the incidence of neurological complications, have failed to stress how frequently the latter form the presenting clinical picture. While reviewing cases of bacterial endocarditis seen in this hospital (Hampton and Harrison, 1967) we noted that the initial problem had often been the differential diagnosis of a neurological syndrome.

This paper describes the presenting neurological manifestations in a series of patients with bacterial endocarditis.

\section{Material}

The hospital notes of all patients recorded as having bacterial endocarditis between January 1955 and December 1965 were consulted. The diagnosis had been proved at necropsy in 29

- Department of the Regius Professor of Medicine, Radcliffe Infirmary, cases, by blood cultures in 63 cases, and in 24 cases the patient had been treated on the strength of the clinical evidence. These three groups provided 116 patients for analysis.

Thirty-three patients presented a problem in neurological diagnosis at the time of their hospital admission, and therefore form the basis of this review. In addition, four patients developed neurological complications after their admission.

As the neurological and neurosurgical departments of this hospital serve the regional area, it was possible that a selected series of patients was being studied. However, only 7 of the 33 patients came because of their neurological problem from outside the area of referral of the general medical cases.

Necropsy information was available in 21 of the cases with neurological features.

\section{Results}

In 22 patients neurological symptoms were the first feature of their bacterial endocarditis, and in 11 others neurological complaints, though following general symptoms, had nevertheless been the reason for admission to hospital. Thus the diagnostic 